Review

\title{
Current Advancement on the Dynamic Mechanism of Gastroesophageal Reflux Disease
}

\author{
Zhi Zheng $1,2,3,4^{*}$, Yuxi Shang $5^{*}$, Ning Wang $6^{*}$, Xiaoye Liu ${ }^{1,2,3,4^{*}}$, Chenglin Xin ${ }^{1,2,3,4}$, Xiaosheng Yan $1,2,3,4$, Yuhao \\ Zhai ${ }^{1,2,3,4}$, Jie Yin ${ }^{1,2,3,4}{ }^{\bowtie}$, Jun Zhang ${ }^{1,2,3,4}$ and Zhongtao Zhang ${ }^{1,2,3,4}$ \\ 1. Department of General Surgery, Beijing Friendship Hospital, Capital Medical University, Beijing, China. \\ 2. Beijing Key Laboratory of Cancer Invasion and Metastasis Research, Beijing, China. \\ 3. National Clinical Research Center for Digestive Diseases, Beijing, China. \\ Beijing Institute of Clinical Medicine, Beijing, China. \\ 5. Department of Hematology, Fuxing Hospital, Eighth Clinical Medical College, Capital Medical University, Beijing, China. \\ 6. Department of Anesthesiology, Beijing Friendship Hospital, Capital Medical University, Beijing, China. \\ *These authors contributed equally to this work. \\ $\triangle$ Corresponding authors: Jun Zhang, MD, PhD, Chief Doctor, Professor, Surgeon, Department of General Surgery, Beijing Friendship Hospital, Capital Medical University, \\ 95 Yong-an Road, Xi-Cheng District, Beijing 100050, China. E-mail: zhangjun5986@ccmu.edu.cn; Tel: +86 13811055986; Jie Yin, MD, PhD, Department of General Surgery, \\ Beijing Friendship Hospital, Capital Medical University, 95 Yong-an Road, Xi-Cheng District, Beijing 100050, China. E-mail: yyyyyj@ccmu.edu.cn; Tel: +86 15011302788.
}

(C) The author(s). This is an open access article distributed under the terms of the Creative Commons Attribution License (https://creativecommons.org/licenses/by/4.0/). See http://ivyspring.com/terms for full terms and conditions.

Received: 2021.07.17; Accepted: 2021.09.19; Published: 2021.10.03

\begin{abstract}
Gastroesophageal reflux disease (GERD) is a common clinical disease associated with upper gastrointestinal motility disorders. Recently, with improvements in living standards and changes in lifestyle and dietary habits, the incidence of GERD has been increasing yearly. However, the mechanism of GERD has not been fully elucidated due to its complex pathogenesis, and this had led to unsatisfactory therapeutic outcomes. Currently, the occurrence and development of GERD involve multiple factors. Its pathogenesis is mainly thought to be related to factors, such as lower esophageal sphincter pressure, transient lower esophageal sphincter relaxation, crural diaphragmatic dysfunction, hiatus hernia, and impaired esophageal clearance. Therefore, explaining the pathogenesis of GERD more clearly and systematically, exploring potential and effective therapeutic targets, and choosing the best treatment methods have gradually become the focus of scholars' attention. Herein, we reviewed current advancements in the dynamic mechanism of GERD to better counsel patients on possible treatment options.
\end{abstract}

Key words: gastroesophageal reflux disease, dynamic mechanism, anti-reflux barrier disruption, esophageal clearance impaired, advancement

\section{Introduction}

Gastroesophageal reflux disease (GERD) is one of the most common upper gastrointestinal tract diseases, which mainly results in acid reflux, heartburn, intractable cough, and asthma caused by reflux of upper gastrointestinal contents into the esophagus $[1,2]$. As the disease progresses, some patients may develop esophagitis, esophageal ulcers, and esophageal stenosis. In severe cases, GERD can lead to Barrett's esophagus or esophageal cancer, which can affect a patient's quality of life and long-term prognosis [3]. Recently, the incidence of GERD has been increasing yearly due to improvements in living standards and changes in lifestyle and dietary habits of people $[4,5]$. However, the pathogenesis of GERD and other different types of dynamic disorders has not yet been fully elucidated, and this has led to unsatisfactory therapeutic outcomes $[6,7]$. Therefore, explaining the pathogenesis of GERD more clearly and systematically, exploring potential and effective therapeutic targets, and selecting the best treatment have gradually become the focus of scholars' attention [8]. Currently, the pathogenesis of GERD is generally believed to be related to reduction in the pressure of the lower esophageal sphincter (LES), transient and excessive lower esophageal sphincter relaxation (TLESR), hiatal hernia, esophageal clearance dysfunction, acid pockets, esophageal hypersensitivity, and mucosal barrier damage [9-14]. Meanwhile, an in-depth study of the pathogenesis of GERD would aid in promoting 
the progression of its diagnosis and treatment, reducing its incidence, and improving the quality of life and prognosis of patients [15]. Therefore, the purpose of this study was to systematically review current research advancements on the dynamic mechanism of GERD, with the aim of providing a reference for clinical practice.

Table 1. Incidence of GERD symptoms in different geographical locations

\begin{tabular}{lllll}
\hline & Number of patients (n) & Incidence (\%) & 95\%CI (\%) & $P$ value \\
\hline North American & 43794 & 15.4 & $10.7-20.9$ & $<0.001$ \\
South American & 24164 & 17.6 & $11.0-25.3$ & $<0.001$ \\
Middle Eastern & 86428 & 15.0 & $11.5-19.0$ & $<0.001$ \\
South Asian & 8864 & 22.1 & $11.5-35.0$ & $<0.001$ \\
Southeast Asian & 58239 & 7.4 & $5.0-10.1$ & $<0.001$ \\
Australasian & 20461 & 14.1 & $12.2-16.2$ & $<0.001$ \\
Northern European & 198686 & 15.5 & $13.6-17.5$ & $<0.001$ \\
Southern European & 19848 & 21.3 & $15.8-27.3$ & $<0.001$ \\
\hline
\end{tabular}

GERD, gastroesophageal reflux disease.

\section{Methods}

We conducted a literature search for published manuscripts on GERD up to August 2021 in PubMed, Web of Science, and EMBASE databases, and employed the following search terms: "gastroesophageal reflux disease," "reflux esophagitis," "epidemiology," "pathogenetic mechanism," "dynamic mechanism, "esophageal motility disorder," "lower esophageal sphincter pressure reduction," "esophageal clearance dysfunction," "hiatal hernia," and "transient lower esophageal sphincter relaxation." Qualitative and quantitative data were extracted by interpreting each paper in cycles to avoid missing potentially valuable data.

\section{Epidemiology of GERD}

GERD is a disease whose treatment requires substantial medical resources [16], and its risk factors include smoking, obesity, alcohol consumption, nonsteroidal anti-inflammatory drugs (NSAIDs), social factors, psychosomatic diseases, and genetic factors [17-21]. Meanwhile, there are also correlation between GERD and ethnicity, Helicobacter pylori infection, gender, age, and lifestyle [22-25]. A study reported that the prevalence of GERD varies greatly in different countries and regions, and its clinical characteristics, etiology, and pathogenesis factors vary [26]. Previous studies have conducted relevant epidemiological investigations on the clinical symptoms and incidence of GERD in different countries and regions [27-31] (Table 1). Overall, the prevalence rate of GERD is relatively high in developed western countries and is low in Asia. Moreover, the severity of the disease in Asia is relatively milder than that in western countries [32-44] (Figure 1). A meta-analysis showed that the prevalence of GERD in western countries is approximately $10-20 \%$, while that in Asian countries is $<10 \%$ [17]. The global incidence of GERD has been increasing annually. Studies have reported that the incidence of GERD in North America is as high as $27.8 \%$, and is $25.9 \%$ in Europe $[8,45,46]$. In addition, Daniele et al. investigated 137,081 cases from 2005 to 2014 and found that the average annual incidence of GERD was 101.3/10,000, which seriously affected people's quality of life and mental state. This is a clinical problem that needs to be solved urgently [47].

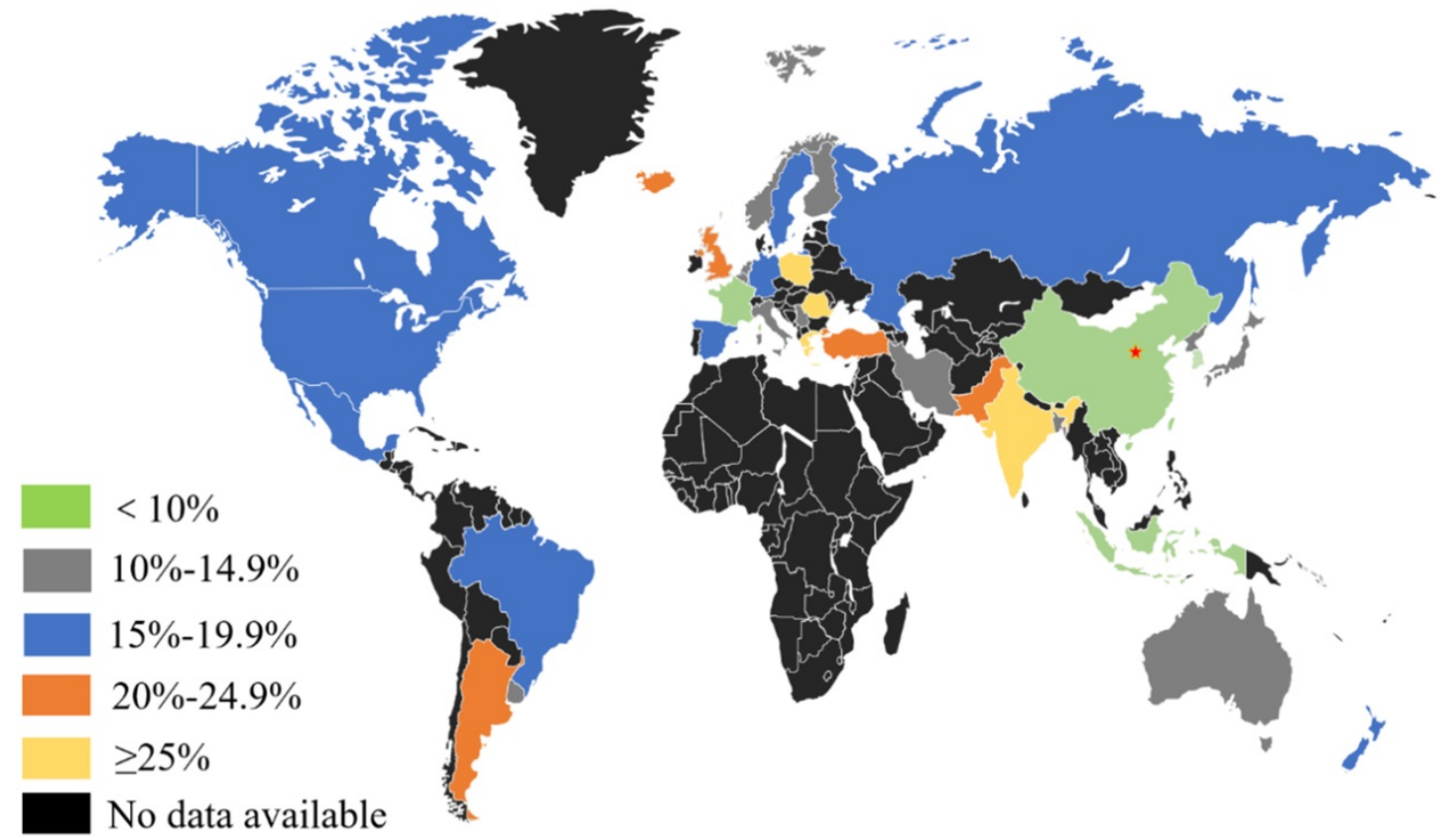

Figure 1. Incidence of GERD symptoms worldwide. Generally, the prevalence rate is relatively high in developed western countries and lower in Asia. 
However, there are relatively few studies on the incidence of GERD. Most of which are only epidemiological surveys conducted in certain regions. Moreover, clinical studies based on the characteristics of the Chinese population are unavailable, and this has led to limitations in the value of the clinical diagnosis and treatment of GERD. Based on this, a large-scale domestic epidemiological survey involving 16,078 patients was conducted. The results showed that the rate of heartburn and/or reflux at least once a week was $5.2 \%(3.2-7.5 \%)$, the prevalence of heartburn at least once a week was $1.8 \%$, the incidence of reflux at least once a week was $4.2 \%$, and the incidence of GERD that met the Montreal definition was $3.1 \%(1.7-5.1 \%)$ [48]. However, the limitation of this study is that clinical data on new onset cases of GERD in Chinese populations were not obtained [48]. Hence, it is necessary for scholars to carry out a larger epidemiological investigation in the future to provide a reference for clinical practice.

\section{Pathogenetic mechanism of GERD}

Usually, the anti-reflux defense mechanism of the esophagus and the erosive effect of refluxed substance on the esophageal mucosa are in equilibrium. When the former's defense mechanism is reduced or the latter's injurious effect is enhanced, the balance is broken, and this may lead to the occurrence of GERD [49]. The primary pathophysiological mechanisms of GERD are anti-reflux barrier function weakening and impaired esophageal clearance function $[50,51]$.

\section{Anti-reflux barrier disruption at the esophageal junction}

\section{Hypotensive lower esophageal sphincter pressure}

The LES is the most important structure of the anti-reflux barrier at the esophagogastric junction [52, 53]. After eating, LES relaxation in healthy people leads to a decrease in LES pressure, which is conducive for the digestion of food in the gastric cavity. At night or when sleeping, LES contraction leads to an increase in LES pressure and this prevents reflux [52, 54] (Figure 2A). Therefore, the pressure difference between the esophagus and the gastric cavity is an important factor in the prevention of reflux. Reflux occurs when the resting pressure of the LES is abnormally low, resulting in a gastric pressure that is higher than the esophageal pressure [55] (Figure 2B). In healthy people, the resting pressure of the LES is approximately $10-30 \mathrm{mmHg}$, as this is a high-pressure zone that is formed by contraction of the LES, which can prevent the reflux of gastric contents and bile into the esophagus [56] (Figure 3A and 3B). In addition, high-resolution esophageal manometry (HRM) has shown that the LES pressure of patients with GERD, especially those with reflux esophagitis, was significantly lower than that of healthy subjects [57, 58]. Compared to healthy subjects, individuals with obesity, pregnancy, or
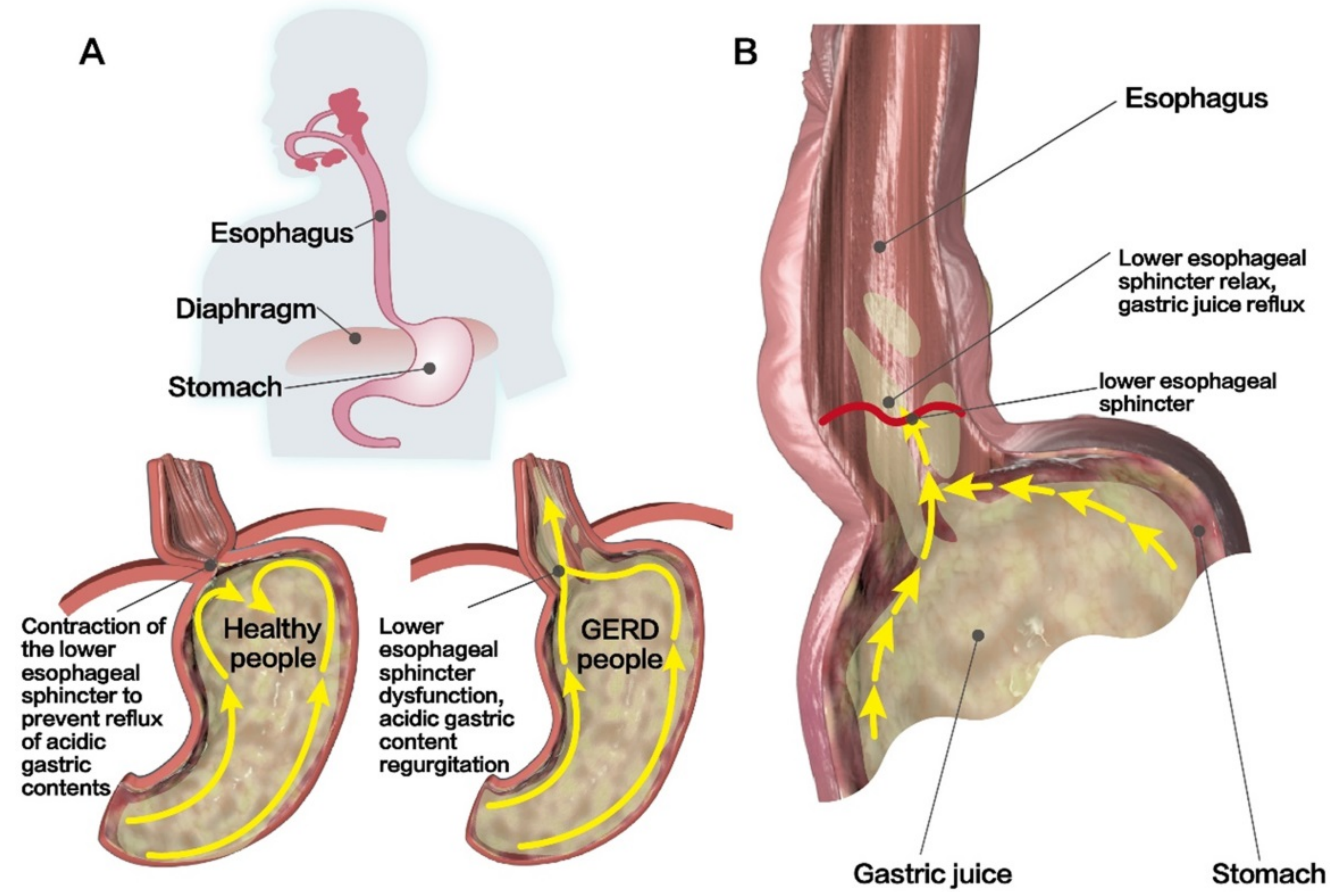

Figure 2. Structural characteristics of the LES. (A) In healthy people, LES contraction can lead to an increased LES pressure that can prevent acidic gastric contents from reflux. However, LES dysfunction in patients with GERD can lead to acidic gastric content regurgitation. (B) Reflux occurs when the resting pressure of LES is abnormally low, resulting in higher gastric pressure than esophageal pressure. 
gastric emptying disorders have been shown to have significantly higher gastric pressure and average gastroesophageal pressure gradient, which may also promote the occurrence of GERD [59-61] (Figure 3C). In addition, another study conducted $\mathrm{pH}$ monitoring on 310 patients with GERD for two consecutive days and found that $83 \%$ of the patients with abnormal $\mathrm{pH}$ values for 2 days had LES damage. Moreover, LES damage was also observed in $35 \%$ of the patients with abnormal $\mathrm{pH}$ levels for only 1 day and in $17 \%$ of those with normal $\mathrm{pH}$ values for 2 days, suggesting that the incidence of GERD was related to LES damage [62]. This may be mainly attributed to the shortened length of LES and decreased resting pressure of LES, which is positively correlated with the degree of esophageal acid exposure. Recent studies have also found that changes in parameters, such as low LES pressure score or low esophagogastric junction (EGJ) contraction integral in high-resolution esophageal manometry may also be closely related to the occurrence of gastroesophageal reflux [15, 63, 64]; however, the value of its clinical application remains to be further explored.

The treatment of GERD mainly includes drug treatment, endoscopic treatment and surgical treatment. In addition to drug treatment, surgical treatment has become the primary therapy [1]. The key to surgery is to fold the fundus of the stomach to surgically restore the structure of the EGJ, the normal anatomical position of the LES, and the length of the LES, through proper suture fixation. Adequate restoration and maintenance of the anti-reflux function of the LES, is required for surgical treatments to achieve a suitable unity of structure and function [65].

\section{Transient lower esophageal sphincter relaxation}

With an in-depth study of the pathogenesis of GERD, it is now generally believed that TLESR is the main cause of gastroesophageal reflux [66]. TLESR refers to the transient spontaneous relaxation of the LES without swallowing. The relaxation time can last for 10-45 s or more, which is often accompanied by reflux of gastric and duodenal fluids [8,67] (Figure 2B). Although TLESR can occur in healthy people with normal LES pressure or in patients with GERD, the refluxed content is different. The former present mostly with gas reflux and most cases have no obvious reflux symptoms, while the latter often presents with acid reflux, which is associated with chronic reflux diseases in most cases [50, 68, 69]. Studies have found that only $40-50 \%$ of TLESR are associated with acid reflux in healthy people, compared to $60-70 \%$ in patients with GERD [70, 71]. Another studies have found that the frequency and duration of TLESR were significantly higher in patients with GERD than in healthy participants, which confirmed that TLESR is an important mechanism that causes GERD reflux symptoms [72]. The mechanism of GERD caused by TLESR may be related to changes in EGJ compliance and the increase in EGJ pressure gradient [73]. In addition, the esophagus will continue to shorten during TLESR due to longitudinal esophageal muscle contraction, thereby promoting reflux [74, 75]. Meanwhile, gastric distention and intractable constipation that cause increased abdominal pressure can also lead to TLESR [70]. To further explore the potential pathogenesis of TLESR, it has been reported that TLESR is a mode of vagus-vagus-mediated conduction $[52,76]$. In the case

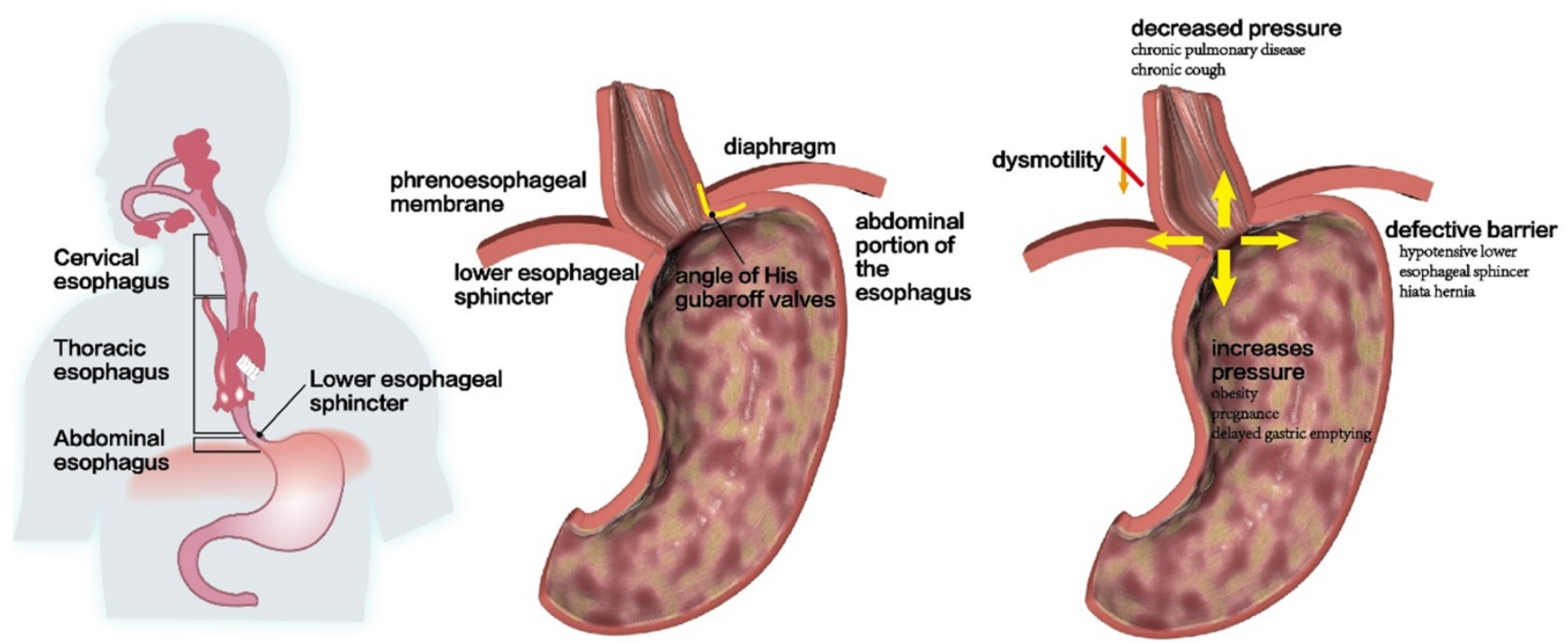

Figure 3. Anti-reflux barrier disruption at the esophageal junction. (A and $\mathbf{B}$ ) In healthy people, the resting pressure of LES, an anti-reflux barrier at the esophagogastric junction, is approximately $10-30 \mathrm{mmHg}$. (C) People with obesity, pregnancy, or gastric emptying disorders had significantly higher gastric pressure and average gastroesophageal pressure gradient, which promoted the GERD occurrence. In addition, hypotensive LES, hiatal hernia, and dysmotility are also related to GERD occurrence. 
of gastric distention, the vagal afferent fibers around the EGJ are activated and the nerve impulses after activation are transmitted along the vagal afferent fibers to the solitary tract nucleus. This subsequently triggers the transmission of signals between the nucleus of the solitary tract (NTS) and the dorsal motor nucleus of the vagus nerve (DMV); finally, nerve impulses are transmitted along the efferent fibers of the vagus to the LES and crural diaphragm, which induces relaxation of the LES, esophageal shortening, and decreased tension of the crural diaphragm. Thus, weakening the role of the anti-reflux barrier and causing the onset of GERD [52, 76] (Figure 4). However, studies have confirmed that $\gamma$-aminobutyric acid receptor agonists have inhibitory effects on afferent vagal signals, signal transmission between the NTS and DMV, and efferent vagal signals. Therefore, to treat GERD, studies have suggested reducing the frequency of TLESR [51, 77, 78]. Animal experiments show that Baclofen, a GABA-B receptor agonist, can effectively prevent the occurrence of TLESR and reflux [79, 80]. Moreover, clinical studies have also confirmed that Baclofen can significantly reduce TLESR in both healthy volunteers and patients with GERD and effectively inhibit acid reflux [81-83]. Therefore, the activation of GABA-B receptors can be used as a therapeutic target to inhibit the excitation of the vagus nerve and reduce the occurrence of TLESR. However, its clinical application has been limited because of the adverse reactions and the short half-life of Baclofen [84]. Therefore, researchers need to further search on potential therapeutic targets to inhibit TLESR and better benefit patients with GERD.

\section{Crural diaphragmatic dysfunction}

The EGJ pressure is mainly composed of the crural diaphragm tension and LES pressure. Among them, the crural diaphragm tension is affected by breathing movement, while LES tension is affected by swallowing movement [85]. Therefore, it is necessary to comprehensively consider the influence of breathing and swallowing when calculating the EGJ pressure (Figure 3B). It has been found that the end-expiratory pressure of the EGJ comes from the LES, while the end-inspiratory pressure comes from the crural diaphragm tension under normal circumstances. Therefore, the abnormal anatomy and function of the crural diaphragm is another important factor that causes gastroesophageal reflux. A previous study found that at rest, the crural diaphragm tension of patients with GERD is significantly lower than that of healthy participants. Moreover, the magnitude of the reduction in tension is positively correlated with the degree of acid reflux, which indicates that a reduced crural diaphragm tension may directly weaken the anti-reflux barrier effect of LES [86]. However, due to the complex anatomical structure and function of the EGJ, evaluation of its anti-reflux barrier function needs to consider the effect of the LES, diaphragm, and respiratory cycle, which is inconvenient for clinical diagnosis and treatment. Therefore, with the development of HRM, the esophageal-gastric junction contraction index (EGJ$\mathrm{CI}$ ), a new parameter, was used in the comprehensive evaluation of EGJ's anti-reflux barrier ability. Its advantage is that it integrates the changes in EGJ respiration, LES length, and pressure, and simplifies the function analysis of the EGJ [87]. Studies have confirmed that there is a significant difference in EGJ-CI between patients with GERD and those of healthy subjects, and this value can reflect the changes in the anti-reflux barrier function of patients with GERD [88]. Jasper et al. performed HRM and 24-hour $\mathrm{pH}$ impedance detection in patients with GERD and in healthy subjects, and found that EGJ-CI was a new parameter that could best summarize EGJ barrier function in the whole HRM measurement. This indicates that EGJ-CI may be the best parameter that can be used to predict pathological reflux. It is also a new indicator of EGJ contraction over time [89]. The assessment of the EGJ barrier function can be improved to some extent. Additionally, another study found that when the cut-off value of EGJ-CI was 30, the sensitivity and specificity of EGJ-CI in predicting the occurrence of GERD were $77.8 \%$ and $81.7 \%$, respectively, indicating that EGJ-CI had good accuracy and specificity in predicting GERD. This further proved the importance of anti-reflux barrier function in the pathogenesis of GERD [90]. Based on this, EGJ-CI was used as a new parameter to reflect the anti-reflux barrier ability of the EGJ in the $3^{\text {rd }}$ edition of the Chicago classification, and it has been widely adopted by scholars gradually [87].

\section{Hiatal hernia}

The formation of hiatal hernia $(\mathrm{HH})$ is the main cause of structural abnormalities at the EGJ, among which the increase in intra-abdominal pressure caused by various reasons is the most common cause. $\mathrm{HH}$ is a disease caused by temporary or permanent entry of abdominal organs or tissue through the esophageal hiatus of the diaphragm into the thoracic cavity. GERD with $\mathrm{HH}$ is commonly seen in clinical settings [10, 91, 92]. $\mathrm{HH}$ can be divided into the following four types: 1) type I is a sliding $\mathrm{HH}$ with a small hernial sac; 2) type II is a parahiatal hernia in which the fundus of the stomach can enter the thoracic cavity through the hiatus; 3 ) type III is a mixed $\mathrm{HH}$, which has the characteristics of type I and 
type II HH. The esophageal hiatus has large defects, but no other organs in the abdominal cavity can enter the thoracic cavity; and 4) type IV is a giant $\mathrm{HH}$ that is similar to a type III HH. In this type, the stomach and other organs pass through the esophageal hiatus and enter the thoracic cavity due to a defect in the huge esophageal hiatus [93, 94] (Figure 5). Among them, type I HH is the most common. However, most patients can remain asymptomatic for life and if symptoms occur, it is likely to be gastroesophageal reflux $[95,96]$. Types II, III, and IV HH are rare, but they often cause severe clinical symptoms and require surgical intervention; therefore, they have important clinical significance $[95,96]$.

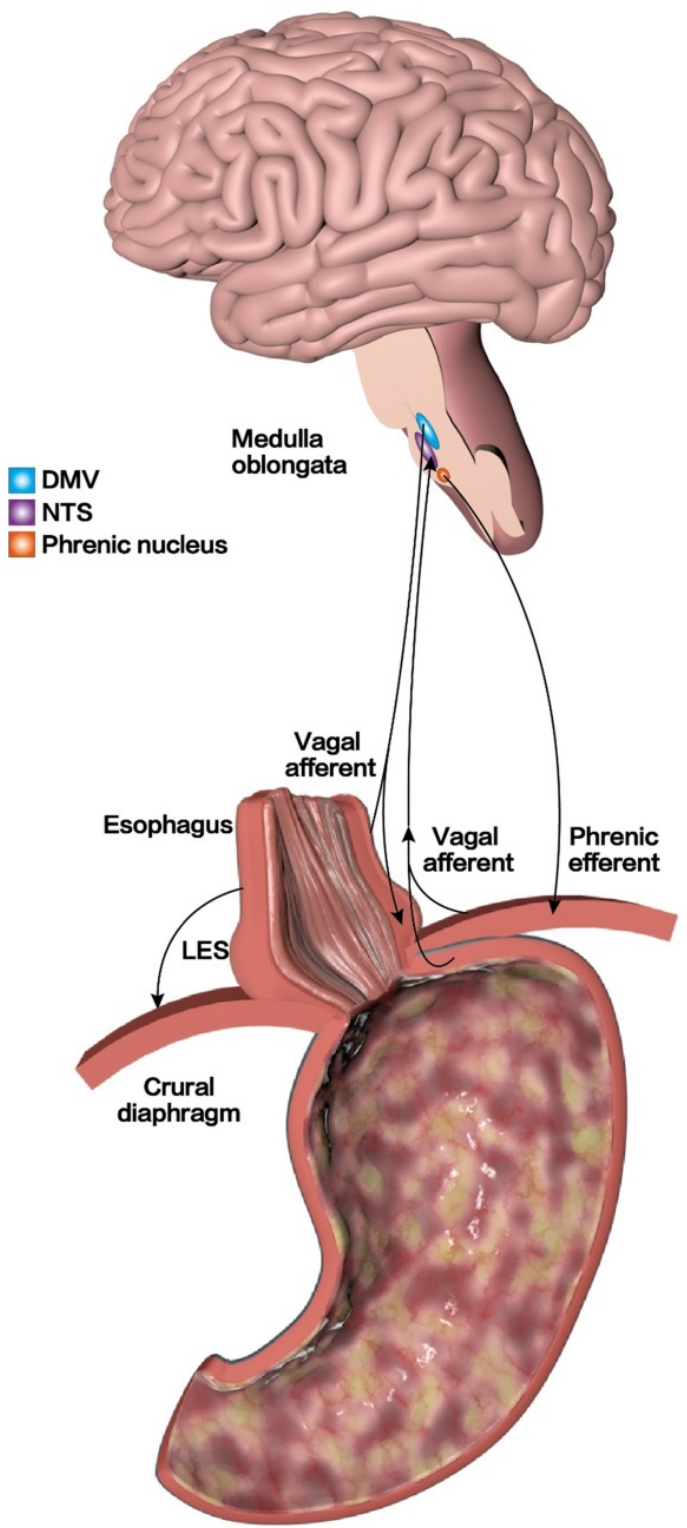

Figure 4. TLESR mechanism of GERD. In the case of gastric distention, the vagal afferent fibers around EGJ are activated, and the nerve impulses after activation are transmitted along the vagal afferent fibers to the solitary tract nucleus. Subsequently, it triggers the signal transmission between the nucleus of the solitary tract (NTS) and the dorsal motor nucleus of the vagus nerve (DMV), and finally nerve impulses are transmitted along the efferent fibers of the vagus to the LES and crural diaphragm, weakening the role of the anti-reflux barrier and causing the onset of GERD.
Studies have confirmed that there are two high-pressure bands in patients with $\mathrm{HH}$ : one is at the level of the LES and the other is at the level of the crural diaphragm, with no overlap between these two bands $[8,97,98]$. Therefore, the synergistic effect of the anti-reflux barrier between the LES and the crural diaphragm is decreased when $\mathrm{HH}$ is formed, which significantly reduces the pressure of the LES and weakens the tension of the crural diaphragm [99]. In addition, the disappearance of the angle of His and the shortening of the abdominal esophagus also destroys the anti-reflux barrier and ultimately increases the probability of reflux [100] (Figure 3C). In addition, $\mathrm{HH}$ can also induce the occurrence of TLESR and its frequency is positively correlated with the size of the $\mathrm{HH}$. This may be because $\mathrm{HH}$ lowers the threshold of TLESR occurrence [101]. However, some studies have suggested that $\mathrm{HH}$ does not increase the frequency of TLESR [102, 103]. The relationship between the two remains unclear, and further research is needed to clarify this. The mechanism through which $\mathrm{HH}$ leads to GERD may also be related to the presence of gastric contents in the hernia sac and reflux of gastric contents when the LES relaxes [8]. In addition, another study found that esophageal peristalsis dysfunction, decreased esophageal clearance, increased frequency of acid reflux, esophageal acid exposure time, and reflux symptoms in $\mathrm{HH}$ patients were related to the size of the $\mathrm{HH}$. The larger the $\mathrm{HH}$, the longer the acid exposure time, and the more severe the esophagitis [104] (Figure 3C). However, there are still many controversies regarding this conclusion. The focus of the debate on whether esophageal peristalsis dysfunction is caused by the $\mathrm{HH}$ itself or secondary reflux esophagitis is still unclear, and needs to be explored further by scholars.

Currently, surgery is the main treatment option for $\mathrm{HH}$. Its most important purpose is to close the hiatus defect, while restoring the position and function of the LES, preventing the contents of the abdominal cavity from moving into the thoracic cavity, and minimizing the incidence of reflux [105].

\section{Esophageal clearance impaired}

Ineffective esophageal motility (IEM)

Esophageal clearance capacity includes the neutralization of reflux by saliva, weight of food itself, and protrusion of esophageal peristalsis [106]. The movement of the esophagus is divided into peristaltic and non-peristaltic contractions. Peristaltic contractions can effectively remove acidic contents of the stomach and duodenum that flow back into the esophagus. However, non-peristaltic contractions are ineffective because of their reduced ability to remove refluxed contents, resulting in prolonged contact with 
acid and further aggravation of esophageal mucosal damage. Therefore, coordinated and effective peristalsis of the esophageal body is the main mechanism to complete bolus transport and timely removal of reflux. When patients with GERD have esophageal body motor dysfunction, the transmission of bolus in the esophagus is delayed, resulting in pathological characteristics, such as pathological transmission patterns [107]. Studies have confirmed that the incidence of IEM in the esophageal body of patients with GERD is $63.95 \%$, and IEM leads to delayed esophageal acid clearance in these patients $[108,109]$.

In addition, studies have divided patients with GERD into two subgroups: acid reflux and non-acid reflux. When acid reflux events increase, there are significant changes in esophageal motility, which manifest as a decrease in LES pressure, LES length, and distal contractile integral (DCI). It has been suggested that acid exposure may be related to esophageal motility disorders [110]. Another study found that, in addition to LES, patients with severe esophagitis also have motor dysfunction in the esophageal body, which causes increased esophageal acid exposure, resulting in esophagitis [111]. The mechanism may be that IEM delays the clearance of esophageal acid, which increases the contact time between the acid and the esophageal mucosa. This causes abnormal changes in the esophageal muscle fibers, nerves, and microenvironment, thus leading to chronic inflammation of the esophageal mucosa, and this aggravates acid reflux [112, 113] (Figure 3C). In addition, some scholars used HRM to perform esophageal motility examination in patients with GERD and IEM, before and after Nissen fundoplication, and found that the postoperative esophageal motility function and clinical symptoms of patients significantly improved compared after the procedure compared to the condition before the procedure [114-116]. Therefore, scholars speculate that abnormal esophageal motility, especially abnormal esophageal body peristalsis and acid reflux, may be mutually causal. However, another study found that the symptoms of patients with GERD were relieved after the administration of proton pump inhibitors; however, there was no significant
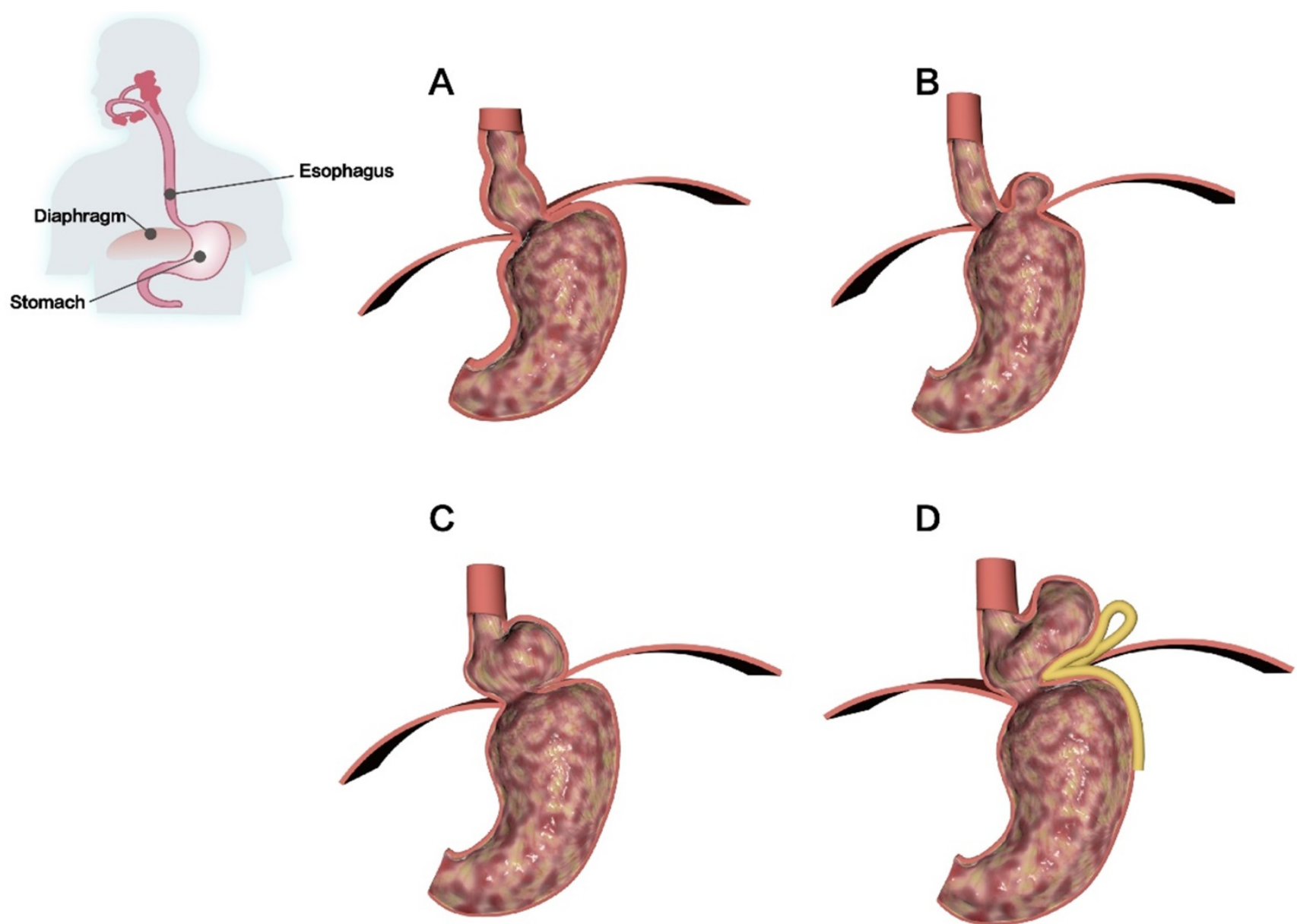

Figure 5. Classification of HH. (A) Type I is a sliding HH with a small hernia sac. (B) Type II is a para-hiatal hernia in which the fundus of the stomach can enter the thoracic cavity through the hiatus. (C) Type III is a mixed HH. The esophageal hiatus has large defects, but no other organ in the abdominal cavity can enter the thoracic cavity. (D) Type $\mathrm{IV}$ is a giant $\mathrm{HH}$ in which the stomach and other organs pass through the esophageal hiatus and enter the thoracic cavity due to the defect of the huge esophageal hiatus. 
improvement in esophageal motility index [108, 117]. Therefore, some scholars believe that reflux causes esophageal inflammation, which in turn causes esophageal peristalsis. However, the current mainstream view still tends to be that GERD is caused by upper gastrointestinal tract dysfunction [52]. Additionally, with the popularization of HRM technology, more attention has been paid to the GERD mechanism of esophageal motility disorders. IEM, as a newly proposed type of esophageal dynamic disorder, plays an important role in the esophageal dynamic characteristics of GERD, the selection of treatment methods, and the elaboration of its pathogenesis [118-120].

Anti-reflux surgery mainly exerts anti-reflux effect by increasing the barrier function of EGJ, which requires individualized treatment based on the comprehensive evaluation of the patients. Among them, anti-reflux surgery mainly includes Nissen, Toupet and Dor fundoplication [121]. Although Nissen fundoplication is the basic operation for antireflux surgery, but it is not suitable for patients with severe esophageal motility disorder [122]. Studies have shown that IEM is not a risk factor for dysphagia after Nissen fundoplication [114]. If IEM patients undergo surgery, the incidence of dysphagia will not increase, but esophageal motor function can improve to a certain extent [114]. Recently, it has also been found that patients with IEM who underwent anti-reflux surgery have significantly improved quality of life [123]. Therefore, the presence of preoperative IEM should not be a contraindication for Nissen fundoplication, and the key to the optimal outcome of laparoscopic anti-reflux surgery is to carefully evaluate the patient's condition based on the objective data, so as to adjust the surgical approach to provide effective reflux control and improve esophageal clearance [123].

\section{Multiple rapid swallowing (MRS)}

During esophageal manometry, MRS can be used to assess the presence of a contraction reserve in the esophageal body [124]. Among them, MRS can inhibit the central and peripheral nervous system as well as the contraction of esophageal smooth muscle, leading to complete and persistent relaxation of the LES. In addition, the last stage of swallowing during MRS is accompanied by a series of powerful esophageal contractions and contractions after LES relaxation. The normal MRS response not only requires a complete inhibition and excitation mechanism to regulate the coordination between the esophageal body and the LES, but also requires the integrity of the esophageal smooth muscle to respond to the strong stimulation at the end of MRS. Therefore, when the esophageal contractile reserve is present, the MRS peristalsis enhancement ratio is $>1[11,125]$. One study confirmed that $65 \%$ of patients with IEM have an abnormal MRS response [126]. Martinucci et al. studied the correlation between the distal contraction integral (DCI) and impedance-pH detection parameters after MRS in 103 patients with heartburn using negative endoscopy. It was also shown that the increase in DCI after MRS was positively correlated with the post-reflux swallow-induced peristaltic wave (PSPW) $(r=0.626, p<0.01)$ and negatively correlated with acid exposure time (AET) $(r=-0.699, p<0.01)$ [127]. Based on this, the Lyon Consensus in 2018 has created a new definition for the diagnosis of GERD [15]. Meanwhile, EGJ classification, EGJ-CI, and MRS peristalsis enhancement ratio were taken as new indicators of esophageal motor function, which will help to further promote the advancement in clinical diagnosis and treatment of GERD [15, 128]. Since the MRS test has been proved to be an effective indicator in the GERD study [7]. Therefore, in the future, the diagnosis of MRS combined with IEM can predict the risk of postoperative dysphagia and guide the selection of treatment modalities.

\section{Conclusion and current problem}

GERD is a complex disease caused by multiple factors, and its pathogenesis has not been fully elucidated. Among them, LES structural abnormalities, hiatal hernia, and esophageal peristalsis dysfunction may play an important role in the pathogenesis of GERD. Although much progress has been made in the pathogenesis of GERD, there are still many problems to be studied, mainly focusing on the following aspects. First, the mechanism of $\mathrm{HH}$ involvement in GERD occurrence is still not fully understood. Second, whether esophageal peristalsis dysfunction is primary or secondary to gastroesophageal reflux and whether it is related to the severity of esophagitis, is unknown. Third, there is a lack of effective parameters to comprehensively evaluate the esophageal clearance rate when reflux occurs. Consequently, in-depth research on the etiology and pathogenesis of GERD in future will help to improve the clinicians' understanding of GERD, promote the advancement of diagnosis and treatment methods, and ultimately find a better therapy to improve the quality of life of patients.

\section{Abbreviations}

GERD: gastroesophageal reflux disease; LES: lower esophageal sphincter; TLESR: lower esophageal sphincter relaxation; NSAIDs: non-steroidal antiinflammatory drugs; EGJ: esophagogastric junction; NTS: nucleus of the solitary tract; DMV: dorsal motor 
nucleus of the vagus nerve; EGJ-CI: esophagealgastric junction contraction index; $\mathrm{HH}$ : hiatal hernia; IEM: ineffective esophageal motility; DCI: distal contractile integral; HRM: high-resolution esophageal manometry; MRS: multiple rapid swallowing; PSPW: post-reflux swallow-induced peristaltic wave; AET: acid exposure time.

\section{Acknowledgements}

\section{Funding}

This study was supported by the Beijing Municipal Science \& Technology Commission (D171100006517003); Research Foundation of Beijing Friendship Hospital, Capital Medical University (Y2018-3); Xicheng District Outstanding Talent Project 2018-2019 (Yuxi Shang); Capital Medical University Education Reform Research Project in 2021 (2021JYY106) and Beijing Municipal Administration of Hospitals Incubating Program (PX2020001).

\section{Author Contributions}

Zhi Zheng, Yuxi Shang, Ning Wang and Xiaoye Liu performed the literature review, drafted the manuscript; Chenglin Xin, Xiaosheng Yan and Yuhao Zhai contributed to the critical review of the manuscript; Jie Yin, Jun Zhang and Zhongtao Zhang supervised the study and contributed to the critical editing of the manuscript. All authors have read and agreed to the published version of the manuscript.

\section{Competing Interests}

The authors have declared that no competing interest exists.

\section{References}

1. Maret-Ouda J, Markar SR, Lagergren J. Gastroesophageal Reflux Disease: A Review. JAMA. 2020; 324: 2536-47.

2. Vakil N, van Zanten SV, Kahrilas P, Dent J, Jones R, Global Consensus G. The Montreal definition and classification of gastroesophageal reflux disease: a global evidence-based consensus. Am J Gastroenterol. 2006; 101: 1900-20; quiz 43.

3. Mehta RS, Staller K, Chan AT. Review of Gastroesophageal Reflux Disease. JAMA. 2021; 325: 1472

4. Sandhu DS, Fass R. Current Trends in the Management of Gastroesophageal Reflux Disease. Gut Liver. 2018; 12: 7-16.

5. Katzka DA, Kahrilas PJ. Advances in the diagnosis and management of gastroesophageal reflux disease. BMJ. 2020; 371: m3786.

6. Aziz Q, Fass R, Gyawali CP, Miwa H, Pandolfino JE, Zerbib F. Functional Esophageal Disorders. Gastroenterology. 2016; 150: 1368-79.

7. Ergun M, Dogan I, Unal S. Ineffective esophageal motility and gastroesophageal reflux disease: a close relationship? Turk J Gastroenterol. 2012; 23 : 627-33.

8. Herregods TV, Bredenoord AJ, Smout AJ. Pathophysiology of gastroesophageal reflux disease: new understanding in a new era. Neurogastroenterol Motil. 2015; 27: 1202-13.

9. Turner B, Helm M, Hetzel E, Schumm M, Gould JC. The relationship between gastroesophageal junction integrity and symptomatic fundoplication outcomes. Surg Endosc. 2020; 34: 1387-92.

10. Schlottmann F, Andolfi C, Herbella FA, Rebecchi F, Allaix ME, Patti MG. GERD: Presence and Size of Hiatal Hernia Influence Clinical Presentation, Esophageal Function, Reflux Profile, and Degree of Mucosal Injury. Am Surg. 2018; 84: 978-82

11. Lin S, Li H, Fang X. Esophageal Motor Dysfunctions in Gastroesophageal Reflux Disease and Therapeutic Perspectives. J Neurogastroenterol Motil. 2019; 25: 499-507.
12. Gyawali CP, Roman S, Bredenoord AJ, Fox M, Keller J, Pandolfino JE, et al. Classification of esophageal motor findings in gastro-esophageal reflux disease: Conclusions from an international consensus group. Neurogastroenterol Motil. 2017; 29: e13104.

13. Rohof WO, Bennink RJ, de Ruigh AA, Hirsch DP, Zwinderman AH, Boeckxstaens GE. Effect of azithromycin on acid reflux, hiatus hernia and proximal acid pocket in the postprandial period. Gut. 2012; 61: 1670-7.

14. Savarino E, Bredenoord AJ, Fox M, Pandolfino JE, Roman S, Gyawali CP, et al. Expert consensus document: Advances in the physiological assessment and diagnosis of GERD. Nat Rev Gastroenterol Hepatol. 2017; 14: 665-76.

15. Gyawali CP, Kahrilas PJ, Savarino E, Zerbib F, Mion F, Smout A, et al. Modern diagnosis of GERD: the Lyon Consensus. Gut. 2018; 67: 1351-62.

16. Peery AF, Crockett SD, Murphy CC, Lund JL, Dellon ES, Williams JL, et al. Burden and Cost of Gastrointestinal, Liver, and Pancreatic Diseases in the United States: Update 2018. Gastroenterology. 2019; 156: 254-72 e11.

17. Eusebi LH, Ratnakumaran R, Yuan Y, Solaymani-Dodaran M, Bazzoli F, Ford AC. Global prevalence of, and risk factors for, gastro-oesophageal reflux symptoms: a meta-analysis. Gut. 2018; 67: 430-40.

18. Ness-Jensen E, Hveem K, El-Serag H, Lagergren J. Lifestyle Intervention in Gastroesophageal Reflux Disease. Clin Gastroenterol Hepatol. 2016; 14: 175-82 e1-3.

19. Yuan LZ, Yi P, Wang GS, Tan SY, Huang GM, Qi LZ, et al. Lifestyle intervention for gastroesophageal reflux disease: a national multicenter survey of lifestyle factor effects on gastroesophageal reflux disease in China. Therap Adv Gastroenterol. 2019; 12: 1-12.

20. Mungan Z, Pinarbasi Simsek B. Which drugs are risk factors for the development of gastroesophageal reflux disease? Turk J Gastroenterol. 2017; 28: S38-S43.

21. Bohmer AC, Schumacher J. Insights into the genetics of gastroesophageal reflux disease (GERD) and GERD-related disorders. Neurogastroenterol Motil. 2017; 29: e13017.

22. Sonnenberg A, Turner KO, Genta RM. Interaction Between Ethnicity and Helicobacter pylori Infection in the Occurrence of Reflux Disease. J Clin Gastroenterol. 2020; 54: 614-9.

23. Corley DA, Kubo A, Zhao W. Abdominal obesity, ethnicity and gastrooesophageal reflux symptoms. Gut. 2007; 56: 756-62.

24. Yamasaki T, Sakiani S, Maradey-Romero C, Mehta R, Sandhu D, Ganocy S, et al. Barrett's esophagus patients are becoming younger: analysis of a large United States dataset. Esophagus. 2020; 17: 190-6.

25. Commisso A, Lim F. Lifestyle Modifications in Adults and Older Adults With Chronic Gastroesophageal Reflux Disease (GERD). Crit Care Nurs Q. 2019; 42: 64-74.

26. Eusebi LH, Cirota GG, Zagari RM, Ford AC. Global prevalence of Barrett's oesophagus and oesophageal cancer in individuals with gastro-oesophageal reflux: a systematic review and meta-analysis. Gut. 2021; 70: 456-63.

27. Richter JE, Rubenstein JH. Presentation and Epidemiology of Gastroesophageal Reflux Disease. Gastroenterology. 2018; 154: 267-76.

28. El-Serag HB, Sweet S, Winchester CC, Dent J. Update on the epidemiology of gastro-oesophageal reflux disease: a systematic review. Gut. 2014; 63: 871-80.

29. Minatsuki C, Yamamichi N, Shimamoto T, Kakimoto H, Takahashi Y, Fujishiro M, et al. Background factors of reflux esophagitis and non-erosive reflux disease: a cross-sectional study of 10,837 subjects in Japan. PLoS One. 2013; 8: e69891.

30. Yamamichi N, Mochizuki S, Asada-Hirayama I, Mikami-Matsuda R, Shimamoto $\mathrm{T}$, Konno-Shimizu $\mathrm{M}$, et al. Lifestyle factors affecting gastroesophageal reflux disease symptoms: a cross-sectional study of healthy 19864 adults using FSSG scores. BMC Med. 2012; 10: 45

31. Hallan A, Bomme M, Hveem K, Moller-Hansen J, Ness-Jensen E. Risk factors on the development of new-onset gastroesophageal reflux symptoms. A population-based prospective cohort study: the HUNT study. Am J Gastroenterol. 2015; 110: 393-400; quiz 1.

32. Diaz-Rubio M, Moreno-Elola-Olaso C, Rey E, Locke GR, 3rd, RodriguezArtalejo F. Symptoms of gastro-oesophageal reflux: prevalence, severity, duration and associated factors in a Spanish population. Aliment Pharmacol Ther. 2004; 19: 95-105.

33. Schwenkglenks M, Marbet UA, Szucs TD. Epidemiology and costs of gastroesophageal reflux disease in Switzerland: a population-based study. Soz Praventivmed. 2004; 49: 51-61.

34. Srinivasan $R$, Tutuian $R$, Schoenfeld $P$, Vela MF, Castell JA, Isaac $T$, et al. Profile of GERD in the adult population of a northeast urban community. J Clin Gastroenterol. 2004; 38: 651-7.

35. Wang JH, Luo JY, Dong L, Gong J, Tong M. Epidemiology of gastroesophageal reflux disease: a general population-based study in Xi'an of Northwest China. World J Gastroenterol. 2004; 10: 1647-51.

36. Camilleri M, Dubois D, Coulie B, Jones M, Kahrilas PJ, Rentz AM, et al. Prevalence and socioeconomic impact of upper gastrointestinal disorders in the United States: results of the US Upper Gastrointestinal Study. Clin Gastroenterol Hepatol. 2005; 3: 543-52.

37. Chen $\mathrm{M}$, Xiong $\mathrm{L}$, Chen $\mathrm{H}, \mathrm{Xu} \mathrm{A}, \mathrm{He} \mathrm{L}, \mathrm{Hu} \mathrm{P}$. Prevalence, risk factors and impact of gastroesophageal reflux disease symptoms: a population-based study in South China. Scand J Gastroenterol. 2005; 40: 759-67.

38. Jafri N, Jafri W, Yakoob J, Islam M, Manzoor S, Jalil A, et al. Perception of gastroesophageal reflux disease in urban population in Pakistan. J Coll Physicians Surg Pak. 2005; 15: 532-4 
39. Moraes-Filho JP, Chinzon D, Eisig JN, Hashimoto CL, Zaterka S. Prevalence of heartburn and gastroesophageal reflux disease in the urban Brazilian population. Arq Gastroenterol. 2005; 42: 122-7.

40. Ronkainen J, Aro P, Storskrubb T, Johansson SE, Lind T, Bolling-Sternevald E, et al. High prevalence of gastroesophageal reflux symptoms and esophagitis with or without symptoms in the general adult Swedish population: a Kalixanda study report. Scand J Gastroenterol. 2005; 40: 275-85.

41. Nocon M, Keil T, Willich SN. Prevalence and sociodemographics of reflux symptoms in Germany--results from a national survey. Aliment Pharmacol Ther. 2006; 23: 1601-5.

42. Wiklund I, Carlsson J, Vakil N. Gastroesophageal reflux symptoms and wellbeing in a random sample of the general population of a Swedish community. Am J Gastroenterol. 2006; 101: 18-28.

43. Nouraie M, Radmard AR, Zaer-Rezaii H, Razjouyan $\mathrm{H}$, Nasseri-Moghaddam S, Malekzadeh R. Hygiene could affect GERD prevalence independently: a population-based study in Tehran. Am J Gastroenterol. 2007; 102: 1353-60.

44. van Kerkhoven LA, Eikendal T, Laheij RJ, van Oijen MG, Jansen JB. Gastrointestinal symptoms are still common in a general Western population. Neth J Med. 2008; 66: 18-22.

45. Bollschweiler E, Knoppe K, Wolfgarten E, Holscher AH. Prevalence of dysphagia in patients with gastroesophageal reflux in Germany. Dysphagia. 2008; 23: 172-6.

46. Moraes-Filho JPP, Domingues G, Chinzon D, Roveda F, Lobao Neto AA, Zaterka S. Impact of Heartburn and Regurgitation on Individuals' Well-Being in the General Population: A Brazilian National Survey. Arq Gastroenterol. 2021; 58: 5-9.

47. Daniele DO, Oh GT, O'Donnell FL, Clark LL. Incidence of gastroesophageal reflux disease (GERD), active component, U.S. Armed Forces, 2005-2014. MSMR. 2015; 22: 14-7.

48. He J, Ma X, Zhao Y, Wang R, Yan X, Yan H, et al. A population-based survey of the epidemiology of symptom-defined gastroesophageal reflux disease: the Systematic Investigation of Gastrointestinal Diseases in China. BMC Gastroenterol. 2010; 10: 94 .

49. Chen J, Brady P. Gastroesophageal Reflux Disease: Pathophysiology, Diagnosis, and Treatment. Gastroenterol Nurs. 2019; 42: 20-8.

50. Usai Satta P, Oppia F, Cabras F. Overview of pathophysiological features of GERD. Minerva Gastroenterol Dietol. 2017; 63: 184-97.

51. Zachariah RA, Goo T, Lee RH. Mechanism and Pathophysiology of Gastroesophageal Reflux Disease. Gastrointest Endosc Clin N Am. 2020; 30: 209-26.

52. Mittal R, Vaezi MF. Esophageal Motility Disorders and Gastroesophageal Reflux Disease. N Engl J Med. 2020; 383: 1961-72.

53. Mittal RK, Balaban DH. The esophagogastric junction. N Engl J Med. 1997; 336: 924-32.

54. Mittal RK, Zifan A, Kumar D, Ledgerwood-Lee M, Ruppert E, Ghahremani G. Functional morphology of the lower esophageal sphincter and crural diaphragm determined by three-dimensional high-resolution esophagogastric junction pressure profile and CT imaging. Am J Physiol Gastrointest Liver Physiol. 2017; 313: G212-G9.

55. Babaei A, Venu M, Naini SR, Gonzaga J, Lang IM, Massey BT, et al. Impaired upper esophageal sphincter reflexes in patients with supraesophageal reflux disease. Gastroenterology. 2015; 149: 1381-91.

56. Roman S, Tutuian R. Esophageal hypertensive peristaltic disorders. Neurogastroenterol Motil. 2012; 24 Suppl 1: 32-9.

57. Yadlapati R. High-resolution esophageal manometry: interpretation in clinical practice. Curr Opin Gastroenterol. 2017; 33: 301-9.

58. Navarro-Rodriguez T, Hashimoto CL, Carrilho FJ, Strauss E, Laudanna AA, Moraes-Filho JP. Reduction of abdominal pressure in patients with ascites reduces gastroesophageal reflux. Dis Esophagus. 2003; 16: 77-82.

59. Menezes MA, Herbella FAM. Pathophysiology of Gastroesophageal Reflux Disease. World J Surg. 2017; 41: 1666-71.

60. Chang P, Friedenberg F. Obesity and GERD. Gastroenterol Clin North Am. 2014; 43: 161-73

61. Sharma P, Yadlapati R. Pathophysiology and treatment options for gastroesophageal reflux disease: looking beyond acid. Ann N Y Acad Sci. 2021; 1486: 3-14.

62. Ayazi S, Hagen JA, Zehetner J, Banki F, Augustin F, Ayazi A, et al. Day-to-day discrepancy in Bravo $\mathrm{pH}$ monitoring is related to the degree of deterioration of the lower esophageal sphincter and severity of reflux disease. Surg Endosc. 2011; 25: 2219-23.

63. Wang D, Patel A, Mello M, Shriver A, Gyawali CP. Esophagogastric junction contractile integral (EGJ-CI) quantifies changes in EGJ barrier function with surgical intervention. Neurogastroenterol Motil. 2016; 28: 639-46.

64. Gor P, Li Y, Munigala S, Patel A, Bolkhir A, Gyawali CP. Interrogation of esophagogastric junction barrier function using the esophagogastric junction contractile integral: an observational cohort study. Dis Esophagus. 2016; 29: $820-8$.

65. Watson DI, Jamieson GG. Antireflux surgery in the laparoscopic era. Br J Surg. 1998; 85: 1173-84.

66. Tack J, Pandolfino JE. Pathophysiology of Gastroesophageal Reflux Disease. Gastroenterology. 2018; 154: 277-88.

67. Roman S, Holloway R, Keller J, Herbella F, Zerbib F, Xiao Y, et al. Validation of criteria for the definition of transient lower esophageal sphincter relaxations using high-resolution manometry. Neurogastroenterol Motil. 2017; 29: e12920.
68. Yu Y, Wen S, Wang S, Shi C, Ding H, Qiu Z, et al. Reflux characteristics in patients with gastroesophageal reflux-related chronic cough complicated by laryngopharyngeal reflux. Ann Transl Med. 2019; 7: 529.

69. Sifrim D, Castell D, Dent J, Kahrilas PJ. Gastro-oesophageal reflux monitoring: review and consensus report on detection and definitions of acid, non-acid, and gas reflux. Gut. 2004; 53: 1024-31.

70. Yachan. N, Zhonggao. W, Jimin. W, Yungang. L, Feng. J, Xiang. G, et al. Diagnosis and treatment of gastroesophageal reflux disease: report of 1014 cases. Chin J Oper Proc Gen Surg (Electronic Edition). 2010; 4: 264-70.

71. Mittal RK, Holloway RH, Penagini R, Blackshaw LA, Dent J. Transient lower esophageal sphincter relaxation. Gastroenterology. 1995; 109: 601-10.

72. Trudgill NJ, Riley SA. Transient lower esophageal sphincter relaxations are no more frequent in patients with gastroesophageal reflux disease than in asymptomatic volunteers. Am J Gastroenterol. 2001; 96: 2569-74.

73. Stefanova DI, Limberg JN, Ullmann TM, Liu M, Thiesmeyer JW, Beninato T, et al. Quantifying Factors Essential to the Integrity of the Esophagogastric Junction During Antireflux Procedures. Ann Surg. 2020; 272: 488-94.

74. Babaei A, Bhargava V, Korsapati $\mathrm{H}$, Zheng WH, Mittal RK. A unique longitudinal muscle contraction pattern associated with transient lower esophageal sphincter relaxation. Gastroenterology. 2008; 134: 1322-31.

75. Leslie E, Bhargava V, Mittal RK. A novel pattern of longitudinal muscle contraction with subthreshold pharyngeal stimulus: a possible mechanism of lower esophageal sphincter relaxation. Am J Physiol Gastrointest Liver Physiol. 2012; 302: G542-7.

76. Mikami DJ, Murayama KM. Physiology and pathogenesis of gastroesophageal reflux disease. Surg Clin North Am. 2015; 95: 515-25.

77. Brohan J, Goudra BG. The Role of GABA Receptor Agonists in Anesthesia and Sedation. CNS Drugs. 2017; 31: 845-56.

78. Auteri M, Zizzo MG, Serio R. GABA and GABA receptors in the gastrointestinal tract: from motility to inflammation. Pharmacol Res. 2015; 93: $11-21$.

79. Boeckxstaens GE, Denison H, Jensen JM, Lehmann A, Ruth M. Translational gastrointestinal pharmacology in the 21st century: 'the lesogaberan story'. Curr Opin Pharmacol. 2011; 11: 630-3.

80. Liu J, Pehlivanov N, Mittal RK. Baclofen blocks LES relaxation and crural diaphragm inhibition by esophageal and gastric distension in cats. Am J Physiol Gastrointest Liver Physiol. 2002; 283: G1276-81.

81. Cossentino MJ, Mann K, Armbruster SP, Lake JM, Maydonovitch C, Wong RK. Randomised clinical trial: the effect of baclofen in patients with gastrooesophageal reflux--a randomised prospective study. Aliment Pharmacol Ther. 2012; 35: 1036-44.

82. Dong $\mathrm{R}, \mathrm{Xu} \mathrm{X}, \mathrm{Yu} \mathrm{L}$, Ding $\mathrm{H}, \mathrm{Pan} \mathrm{J}, \mathrm{Yu} \mathrm{Y}$, et al. Randomised clinical trial: gabapentin vs baclofen in the treatment of suspected refractory gastrooesophageal reflux-induced chronic cough. Aliment Pharmacol Ther. 2019; 49: 714-22.

83. Beaumont $\mathrm{H}$, Boeckxstaens GE. Does the presence of a hiatal hernia affect the efficacy of the reflux inhibitor baclofen during add-on therapy? Am J Gastroenterol. 2009; 104: 1764-71.

84. Lehmann A. GABAB receptors as drug targets to treat gastroesophageal reflux disease. Pharmacol Ther. 2009; 122: 239-45.

85. Mittal RK, Shaffer HA, Parollisi S, Baggett L. Influence of breathing pattern on the esophagogastric junction pressure and esophageal transit. Am J Physiol. 1995; 269: G577-83.

86. Pandolfino JE, Kim H, Ghosh SK, Clarke JO, Zhang Q, Kahrilas PJ. Highresolution manometry of the EGJ: an analysis of crural diaphragm function in GERD. Am J Gastroenterol. 2007; 102: 1056-63.

87. Kahrilas PJ, Bredenoord AJ, Fox M, Gyawali CP, Roman S, Smout AJ, et al. The Chicago Classification of esophageal motility disorders, v3.0. Neurogastroenterol Motil. 2015; 27: 160-74.

88. Nicodeme F, Pipa-Muniz M, Khanna K, Kahrilas PJ, Pandolfino JE. Quantifying esophagogastric junction contractility with a novel HRM topographic metric, the EGJ-Contractile Integral: normative values and preliminary evaluation in PPI non-responders. Neurogastroenterol Motil. 2014; 26: 353-60.

89. Jasper D, Freitas-Queiroz N, Hollenstein M, Misselwitz B, Layer P, NavarroRodriguez T, et al. Prolonged measurement improves the assessment of the barrier function of the esophago-gastric junction by high-resolution manometry. Neurogastroenterol Motil. 2017; 29: e12925.

90. Ham H, Cho YK, Lee $\mathrm{HH}$, Yoon SB, Lim CH, Kim JS, et al. Esophagogastric junction contractile integral and morphology: Two high-resolution manometry metrics of the anti-reflux barrier. J Gastroenterol Hepatol. 2017; 32: 1443-9.

91. Yu HX, Han CS, Xue JR, Han ZF, Xin H. Esophageal hiatal hernia: risk, diagnosis and management. Expert Rev Gastroenterol Hepatol. 2018; 12: 319-29.

92. Zheng Z, Zhang W, Xin C, Zeng N, Li M, Liu X, et al. Laparoscopic total left-side surgical approach versus traditional bilateral surgical approach for treating hiatal hernia: a study protocol for a randomized controlled trial. Ann Transl Med. 2021; 9: 951

93. Baiu I, Lau J. What Is a Paraesophageal Hernia? JAMA. 2019; 322: 2146.

94. Peters JH. SAGES guidelines for the management of hiatal hernia. Surg Endosc. 2013; 27: 4407-8.

95. Kumar D, Zifan A, Ghahremani G, Kunkel DC, Horgan S, Mittal RK. Morphology of the Esophageal Hiatus: Is It Different in 3 Types of Hiatus Hernias? J Neurogastroenterol Motil. 2020; 26: 51-60. 
96.Cha RR. Find Out the Differences by Types of Hiatal Hernia! J Neurogastroenterol Motil. 2020; 26: 4-5.

97. van Herwaarden MA, Samsom M, Smout AJ. The role of hiatus hernia in gastro-oesophageal reflux disease. Eur J Gastroenterol Hepatol. 2004; 16: 831-5.

98. Kahrilas PJ, Lin S, Chen J, Manka M. The effect of hiatus hernia on gastro-oesophageal junction pressure. Gut. 1999; 44: 476-82.

99. MA ES, Nobre RA, Bezerra PC, Dos Santos AA, Sifrim D. Anatomical and functional deficiencies of the crural diaphragm in patients with esophagitis. Neurogastroenterol Motil. 2017; 29: e12899.

100. Xie C, Wang J, Li Y, Tan N, Cui Y, Chen M, et al. Esophagogastric Junction Contractility Integral Reflect the Anti-reflux Barrier Dysfunction in Patients with Gastroesophageal Reflux Disease. J Neurogastroenterol Motil. 2017; 23: 27-33.

101. Sifrim D, Zhang X. Pathophysiology of GERD in China: the same factors at a lower scale. Am J Gastroenterol. 2004; 99: 2094-7.

102. Fiorentino E. The consumption of snacks and soft drinks between meals may contribute to the development and to persistence of gastro-esophageal reflux disease. Med Hypotheses. 2019; 125: 84-8.

103. Farre R. Pathophysiology of gastro-esophageal reflux disease: a role for mucosa integrity? Neurogastroenterol Motil. 2013; 25: 783-99.

104. Franzen T, Tibbling L. Is the severity of gastroesophageal reflux dependent on hiatus hernia size? World J Gastroenterol. 2014; 20: 1582-4.

105. Sfara A, Dumitrascu DL. The management of hiatal hernia: an update on diagnosis and treatment. Med Pharm Rep. 2019; 92: 321-5.

106. Aspirot A, Faure C. Esophageal dysmotility: characterization and pathophysiology. Dis Esophagus. 2013; 26: 405-9.

107. Savarino E, Gemignani L, Pohl D, Zentilin P, Dulbecco P, Assandri L, et al. Oesophageal motility and bolus transit abnormalities increase in parallel with the severity of gastro-oesophageal reflux disease. Aliment Pharmacol Ther. 2011; 34: 476-86.

108. Shetler KP, Bikhtii S, Triadafilopoulos G. Ineffective esophageal motility: clinical, manometric, and outcome characteristics in patients with and without abnormal esophageal acid exposure. Dis Esophagus. 2017; 30: 1-8.

109. Mello MD, Shriver AR, Li Y, Patel A, Gyawali CP. Ineffective esophageal motility phenotypes following fundoplication in gastroesophageal reflux disease. Neurogastroenterol Motil. 2016; 28: 292-8.

110. Jiang LQ, Ye BX, Wang MF, Lin L. Acid exposure in patients with gastroesophageal reflux disease is associated with esophageal dysmotility. J Dig Dis. 2019; 20: 73-7.

111. Liu L, Li S, Zhu K, Yu W, Wang H, Guo J, et al. Relationship between esophageal motility and severity of gastroesophageal reflux disease according to the Los Angeles classification. Medicine (Baltimore). 2019; 98: e15543.

112. Porter RF, Kumar N, Drapekin JE, Gyawali CP. Fragmented esophageal smooth muscle contraction segments on high resolution manometry: a marker of esophageal hypomotility. Neurogastroenterol Motil. 2012; 24: 763-8, e353.

113. Ribolsi M, Balestrieri P, Emerenziani S, Guarino MP, Cicala M. Weak peristalsis with large breaks is associated with higher acid exposure and delayed reflux clearance in the supine position in GERD patients. Am J Gastroenterol. 2014; 109: 46-51.

114. Simic AP, Skrobic OM, Gurski RR, Sljukic VM, Ivanovic NR, Pesko PM. Can different subsets of ineffective esophageal motility influence the outcome of nissen fundoplication? J Gastrointest Surg. 2014; 18: 1723-9.

115. Laliberte AS, Louie BE, Wilshire CL, Farivar AS, Bograd AJ, Aye RW. Ineffective esophageal motility is not a contraindication to total fundoplication. Surg Endosc. 2020; 35: 4811-6.

116. Nikolic M, Schwameis K, Kristo I, Paireder M, Matic A, Semmler G, et al. Ineffective Esophageal Motility in Patients with GERD is no Contraindication for Nissen Fundoplication. World J Surg. 2020; 44: 186-93.

117. Chen CL, Yi CH, Liu TT, Orr WC. Altered sensorimotor responses to esophageal acidification in older adults with GERD. Scand J Gastroenterol. 2010; 45: 1150-5.

118. Frazzoni M, de Bortoli N, Frazzoni L, Tolone S, Savarino V, Savarino E. Impedance-pH Monitoring for Diagnosis of Reflux Disease: New Perspectives. Dig Dis Sci. 2017; 62: 1881-9.

119. Ang D, Lee YY, Clarke JO, Lynch K, Guillaume A, Onyimba F, et al. Diagnosis of gastroesophageal reflux: an update on current and emerging modalities. Ann N Y Acad Sci. 2020; 1481: 154-69.

120. Gyawali CP, Sifrim D, Carlson DA, Hawn M, Katzka DA, Pandolfino JE, et al. Ineffective esophageal motility: Concepts, future directions, and conclusions from the Stanford 2018 symposium. Neurogastroenterol Motil. 2019; 31: e13584.

121. Patti MG. An Evidence-Based Approach to the Treatment of Gastroesophageal Reflux Disease. JAMA Surg. 2016; 151: 73-8.

122. Fibbe C, Layer P, Keller I, Strate U, Emmermann A, Zornig C. Esophageal motility in reflux disease before and after fundoplication: a prospective, randomized, clinical, and manometric study. Gastroenterology. 2001; 121: 5-14.

123. Addo A, George P, Zahiri HR, Park A. Patients with ineffective esophageal motility benefit from laparoscopic antireflux surgery. Surg Endosc. 2021; 35: 4459-68.

124. Mauro A, Consonni D, Penagini R. Rapid drink challenge and multiple rapid swallowing: Reproducibility of esophageal function assessment. Neurogastroenterol Motil. 2017; 29: e13071.
125. Tadros M, Tran V, Shah V, Yodice M. Patterns of esophageal dysmotility elicited by multiple rapid swallows. Esophagus. 2021; 18: 353-61.

126. Fornari F, Bravi I, Penagini R, Tack J, Sifrim D. Multiple rapid swallowing: a complementary test during standard oesophageal manometry. Neurogastroenterol Motil. 2009; 21: 718-e41.

127. Martinucci I, Savarino EV, Pandolfino JE, Russo S, Bellini M, Tolone S, et al. Vigor of peristalsis during multiple rapid swallows is inversely correlated with acid exposure time in patients with NERD. Neurogastroenterol Motil. 2016; 28: 243-50.

128. Yadlapati R, Pandolfino JE, Fox MR, Bredenoord AJ, Kahrilas PJ. What is new in Chicago Classification version 4.0? Neurogastroenterol Motil. 2021; 33: e14053. 